Document downloaded from:

http://hdl.handle.net/10251/143780

This paper must be cited as:

Lerma Elvira, C.; Barreira, E.; Almeida, R. (01-0). A discussion concerning active infrared thermography in the evaluation of buildings air infiltration. Energy and Buildings. 168:56-66. https://doi.org/10.1016/j.enbuild.2018.02.050

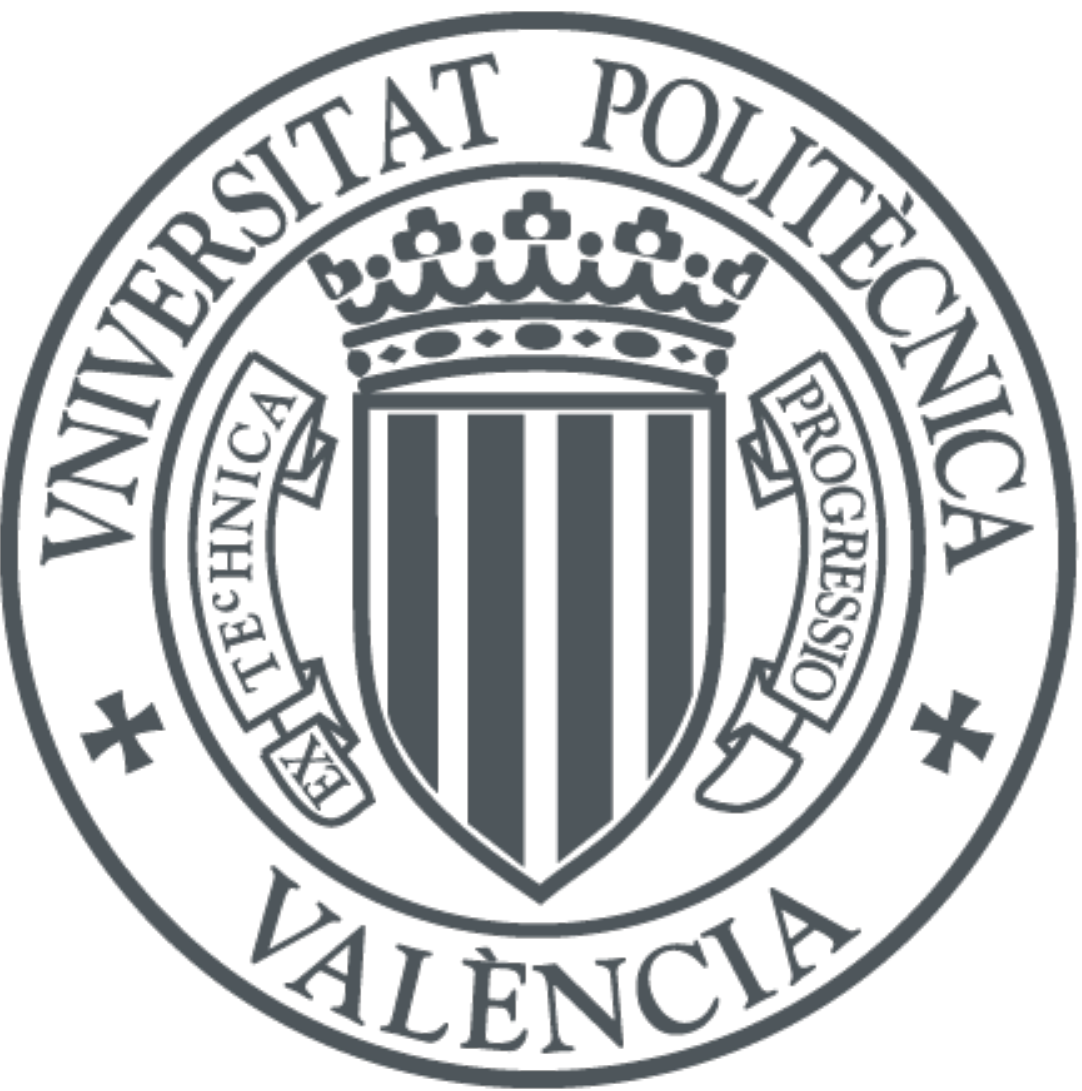

The final publication is available at

https://doi.org/10.1016/j.enbuild.2018.02.050

Copyright Elsevier

Additional Information 


\title{
A DISCUSSION CONCERNING ACTIVE INFRARED THERMOGRAPHY IN THE EVALUATION OF BUILDINGS AIR INFILTRATION
}

\author{
Carlos Lerma $^{(1)}$, Eva Barreira ${ }^{(2)^{*}}$, Ricardo M.S.F. Almeida ${ }^{(2,3)}$
}

(1) Dpt. Architectural Constructions, Universitat Politècnica de València. Camino de Vera s/n, 46022 Valencia, Spain.

(2) CONSTRUCT-LFC, Faculty of Engineering (FEUP), University of Porto, Rua Dr. Roberto Frias s/n, 4200-465 Porto, Portugal.

(3) CI\&DETS - Polytechnic Institute of Viseu, School of Technology and Management, Department of Civil Engineering, Campus Politécnico de Repeses, 3504-510 Viseu, Portugal

*Corresponding author: Eva Barreira (barreira@fe.up.pt)

\begin{abstract}
The EU is strongly committed to energy saving in buildings. Air leaks through the building envelope represent a significant percentage of buildings energy consumption. Locating and minimizing air leaks is thus necessary to optimize energy efficiency.

This work presents the results of an experimental campaign that aimed to promote a discussion concerning the opportunities and constraints of using active IRT to detect air leakage points. The potential of active IRT was evaluated both in a qualitative approach, by comparing the thermograms with the ones obtained with passive IRT, and in a quantitative one, by testing methods of numerically interpret the thermograms.

The results allowed concluding that active IRT increases the thermal contrast and the affected area, proving that active IRT combined with pressure differences is an effective methodology for detecting air infiltrations. In the quantitative approach different numerical methods can be used. Their selection depends on the aims of the study, as they can highlight different perspectives of the phenomenon.
\end{abstract}

KEYWORDS: active infrared thermography, qualitative analysis, quantitative analysis, leakage points, airtightness.

\section{INTRODUCTION}

The EU and its member countries are committed to energy saving. The aim is to achieve a rational use of the energy required for buildings, reducing their consumption to sustainable limits [1]. The EU has committed itself to reduce the Union's energy consumption by $20 \%$ before 2020. To that end, buildings have to consume more efficiently and their energy loses must be minimized. This is achieved through good construction design for new buildings. In existing buildings, it is very important to locate and correct, if possible, thermal losses through the envelope, which, broadly speaking, can derive from heat transfer and ventilation, including infiltration.

According to recent studies, infiltrations can account between $10 \%$ and $50 \%$ of the energy demand [2-6]. In this sense, the airtightness of buildings is an important parameter that is 
necessary to know. The most common procedure to quantify the buildings airtightness is the Blower Door Test, which, through fan pressurization, applies a certain pressure difference, usually in steps of 10-50 Pa [5,7], between the inner space of the building and the outside while measuring the corresponding airflow. The Standard EN 13829:2006 [8] describes the methodology for measuring the air leakages through a building envelope with the Blower Door Test. However, this methodology cannot detect the location of the leakage points in the building envelope.

Infrared thermography (IRT) can be used for the evaluation of the surface temperatures of the facades. This technique is contactless and non-destructive and allows thermal images (thermograms) to be generated. It has already been widely used in the study of the energy efficiency of buildings [9-16], the pathology of building materials [17], as a tool for building diagnosis and definition of construction details [18-25], to detect moisture in building components [26-33], as a conservation evaluation tool for historic buildings [34-38] and to assess thermal comfort [39].

Air infiltration causes temperature differences around the leakage points on the building surface, which can be detected by IRT. These areas can be observed from the inside when buildings are depressurized [7,40-42]. The dimension of this thermal contrast zone depends mainly on the geometry of the defect and the pressure difference between indoors and outdoors [9]. Air leakages through building envelopes have already been analysed through IRT but only using a qualitative approach and passive methods [8, 9,25,38-48].

While passive IRT uses no external excitation energy to highlight the defective area, active IRT is based in using the energy of artificial heat sources to further enhance the thermal contrast between the sound and the defective areas [49-52]. Based on the characteristics of the materials, halogen lamps [52], ultraviolet radiation, flash [53], lasers or infrared lamps can be used as heat source. Active IRT has also been used in many situations to investigate building materials and their defects $[54,55]$ through the quantitative analysis of transient thermal data $[52,56,57]$.

By increasing the temperature gradient, active IRT can be particularly effective in the detection of leakage points, especially in moderate climates where the indoor/outdoor temperature difference is not large. The advantages of using active can be leveraged by both qualitative and quantitative interpretation of the thermograms. However, there is a lack in the literature regarding this specific issue. Therefore, this work aims to promote a discussion concerning the opportunities and constraints of using active IRT to detect leakage points. The potential of active IRT is evaluated both in a qualitative approach, by comparing the thermograms with the ones obtained with passive IRT, and in a quantitative one, by testing methods of numerically interpret the thermograms.

\section{FRAMEWORK}

\subsection{Case study}

To carry out this experimental campaign, a room of a residential multi-storey building constructed in 1980 and located in Matosinhos (northwest of Portugal) was considered. More information about the room characteristics can be found in Barreira et al. [7]. The room has a single window with a roller shutter handle manually controlled and there are no air inlet devices (Figure 1). 

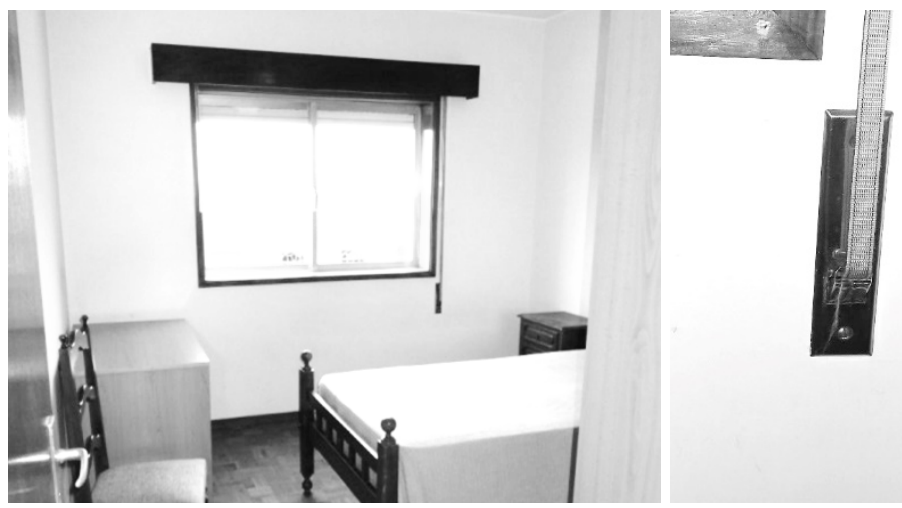

Figure 1: Room under study and roller shutter handle manually controlled.

To assess air leakage only the bottom of the roller shutter handle was considered as previous tests pointed that, due to the localised nature of this specific leakage point, it was easier to be identified [7]. However, two different positions of the IR camera were assessed: (i) IR camera perpendicular to the roller shutter handle (PP); (ii) IR camera parallel to the roller shutter handle (PL). A cardboard sheet was used as a physical support enabling the detection of air infiltration in the thermal images, because it has thermal properties similar to the wall. In scenario PP the cardboard sheet was placed in front of the leakage point, parallel to the wall surface, and in scenario PL the cardboard sheet was placed perpendicular to the leakage point and the wall (Figure 2a and Figure 2b).

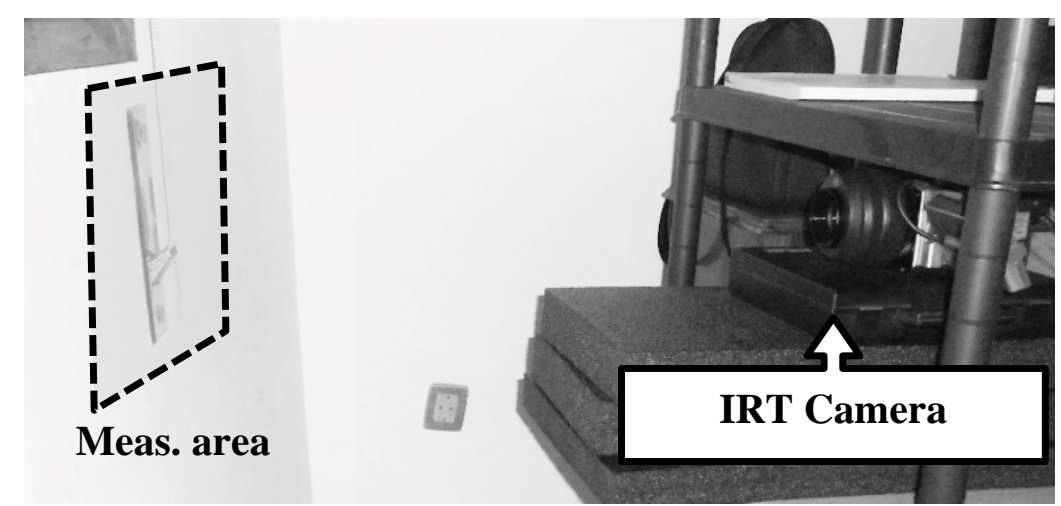

(a)

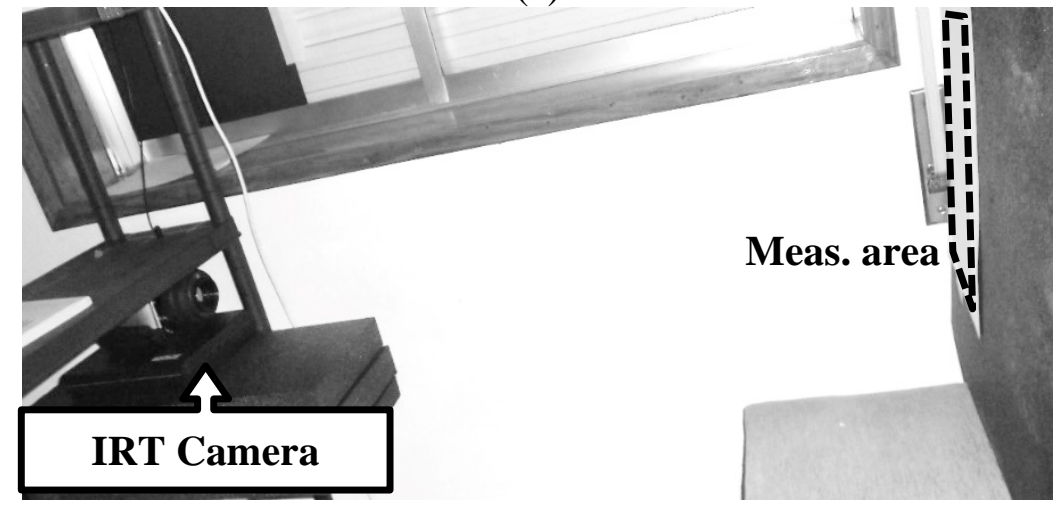

(c)

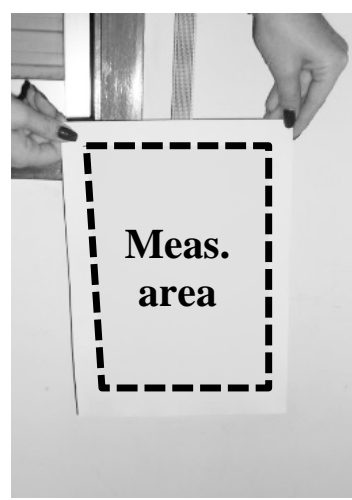

(b)

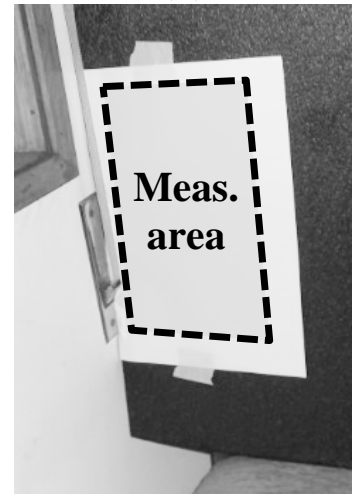

(d)

Figure 2: Position of the IR camera and of the cardboard sheet: (a) and (b) implemented in testing scenario PP; (c) and (d) implemented in testing scenario PL. 


\subsection{Equipment}

During this test campaign an IR camera, a temperature and relative humidity sensor, a portable weather station and a blower door apparatus were used. All devices were properly calibrated before the measurements according to the operation manual. The reflection calibration and ambient and background compensation of the IR camera were implemented before each measurement. Table 1 presents the main characteristics of the IR camera. To implement the active approach an IR lamp of $2500 \mathrm{~W}$ was used.

Table 1: Main characteristics of the IR camera.

\begin{tabular}{|l|c|}
\hline Measuring range & $-20^{\circ} \mathrm{C}$ to $100^{\circ} \mathrm{C}$ \\
\hline Accuracy & $\pm 2^{\circ} \mathrm{C}$ or $\pm 2 \%$ of the reading \\
\hline Resolution & $0.06^{\circ} \mathrm{C}$ at $30^{\circ} \mathrm{C}$ \\
\hline Spectral range & 8.0 to $14.0 \mu \mathrm{m}$ \\
\hline Thermal image & $320(\mathrm{H}) \times 240(\mathrm{~V})$ pixels \\
\hline Field of view & $21.7^{\circ}(\mathrm{H}) \times 16.4^{\circ}(\mathrm{V})$ \\
\hline I.F.O.V & $1.2 \mathrm{mrad}$ \\
\hline Focusing range & $50 \mathrm{~cm}$ to infinite \\
\hline Detector & Uncooled focal plane array (microbolometer) \\
\hline
\end{tabular}

Air temperature and relative humidity were recorded using a 2-channel data logger, with a precision of $\pm 0.35^{\circ} \mathrm{C}$ and $\pm 2.5 \%$ and a resolution of $0.03^{\circ} \mathrm{C}$ and $0.03 \%$, for temperature and relative humidity, respectively. The blower door model has a maximum flow at $50 \mathrm{~Pa}$ test pressure of $10194 \mathrm{~m}^{3} / \mathrm{h}$ and minimum flow at $10 \mathrm{~Pa}$ of $8.5 \mathrm{~m}^{3} / \mathrm{h}$. The gauge accuracy is $\pm 1 \mathrm{~Pa}$ or $\pm 2 \%$, whichever is greater.

The weather station collects outdoor temperature (accuracy of $\pm 1^{\circ} \mathrm{C}$ and resolution of $0.1^{\circ} \mathrm{C}$ ), relative humidity (accuracy of $\pm 5 \%$ and resolution of $1 \%$ ), wind speed (between 0 and $89.3 \mathrm{~m} / \mathrm{s}$ with an accuracy $\pm 0.9 \mathrm{~m} / \mathrm{s}+5 \%$ ) and wind direction (accuracy of $\pm 11.25^{\circ}$ and resolution of $22.5^{\circ}$ ).

\subsection{Methodology}

To assess the air leakage on the bottom of the roller shutter handle the room was depressurized by the mechanical extract fan used in the Blower Door Test. To illustrate this phase and the equipment used see [7]. IRT active approach was used as the cardboard sheet used as physical support was heated during 30 seconds before each measurement. The emissivity of the cardboard sheet (white coloured) is 0.90 . It was measured with a portable emissometer.

The tests were performed in eight different days, with different outdoor and indoor climatic conditions (Table 2 and Table 3). In scenario PP each day included two measurements at different pressure differences (85 Pa and $180 \mathrm{~Pa}$ ), controlled by the Blower Door algorithm. Immediately after the desired pressure difference was guaranteed, the heated cardboard sheet was placed in front of the leakage point and five thermal images were taken each fifteen seconds. Sixteen measurements were performed in this scenario.

In scenario PL, to highlight the differences between active and passive IRT, both methods were tested. Each day included only one measurement with variable pressure differences (0 $\mathrm{Pa}, 25 \mathrm{~Pa}, 75 \mathrm{~Pa}, 175 \mathrm{~Pa}$ and $225 \mathrm{~Pa}$ ). Sequential thermal images were taken as the five different levels of pressure difference were established. Once more, pressure differences were guaranteed by the Blower Door algorithm. 
Table 2: Climatic conditions during scenario PP

\begin{tabular}{|c|c|c|c|c|c|c|c|c|c|}
\hline & & Day 1 & Day 2 & Day 3 & Day 4 & Day 5 & Day 6 & Day 7 & Day 8 \\
\hline \multirow{4}{*}{ 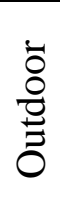 } & Temperature $\left({ }^{\circ} \mathrm{C}\right)$ & 24.8 & 14.2 & 20.3 & 15.5 & 13.1 & 18.5 & 16.9 & 11.1 \\
\hline & Relative Humidity (\%) & 34 & 100 & 76 & 87 & 100 & 65 & 86 & 79 \\
\hline & Wind speed (m/s) & 5.0 & 1.4 & 1.0 & 1.1 & 0.9 & 4.4 & 2.4 & 2.6 \\
\hline & Wind direction $\left(^{\circ}\right)$ & 282 & 145 & 204 & 196 & 251 & 138 & 91 & 76 \\
\hline \multirow{2}{*}{ ت્ધ } & Temperature $\left({ }^{\circ} \mathrm{C}\right)$ & 23.6 & 22.9 & 21.8 & 15.6 & 20.5 & 17.4 & 19.1 & 19.8 \\
\hline & Relative Humidity (\%) & 44 & 63 & 76 & 72 & 63 & 82 & 82 & 53 \\
\hline
\end{tabular}

Table 3: Climatic conditions during scenario PL

\begin{tabular}{|c|c|c|c|c|c|c|c|c|c|}
\hline & & Day 1 & Day 2 & Day 3 & Day 4 & Day 5 & Day 6 & Day 7 & Day 8 \\
\hline \multirow{4}{*}{ 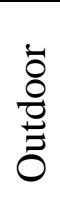 } & Temperature $\left({ }^{\circ} \mathrm{C}\right)$ & 25.6 & 14.3 & 20.4 & 17.2 & 12.9 & 18.4 & 17.3 & 11.5 \\
\hline & Relative Humidity (\%) & 33 & 100 & 75 & 77 & 100 & 68 & 80 & 79 \\
\hline & Wind speed (m/s) & 2.1 & 1.3 & 1.1 & 1.3 & 0.9 & 4.2 & 2.5 & 2.3 \\
\hline & Wind direction $\left(^{\circ}\right)$ & 190 & 168 & 229 & 267 & 283 & 146 & 122 & 72 \\
\hline \multirow{2}{*}{ 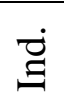 } & Temperature $\left({ }^{\circ} \mathrm{C}\right)$ & 23.5 & 22.2 & 22.3 & 21.8 & 20.9 & 18.7 & 22.4 & 19.9 \\
\hline & Relative Humidity (\%) & 45 & 64 & 77 & 57 & 62 & 80 & 70 & 50 \\
\hline
\end{tabular}

\section{QUALITATIVE ANALYSIS}

The results obtained in PP scenario exposed the cooling effect of time and increased pressure difference. Figure 3 shows the thermal images of the bottom of the roller shutter handle when the IR camera is in PP scenario, at $85 \mathrm{~Pa}$ and $180 \mathrm{~Pa}$. The images taken in Day 4 were selected as an example since the conclusions were identical in the other days. The difference between the two pressure differences is highlighted as the temperatures reached with $\Delta P=85 \mathrm{~Pa}$ (left) and $\Delta P=180 \mathrm{~Pa}$ (right) are simultaneously observed. For both pressure differences the air leakage is detected by a more pronounced decrease of the cardboard sheet surface temperature in the area aligned with the airflow. The relevant temperature range is between 20 and $30^{\circ} \mathrm{C}$, although for $\mathrm{t}=0$ the cardboard temperature was higher, but this is not significant. When the pressure difference increases, the temperature decreases faster as can be observed in the four time-steps by a larger colder area. Moreover, one should stress that a significant temperature drop is already observed in the initial instants $(\mathrm{t}=15 \mathrm{~s})$.

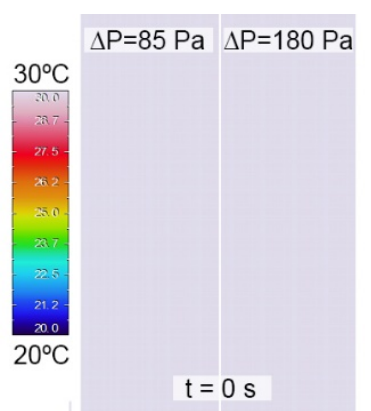

(a)

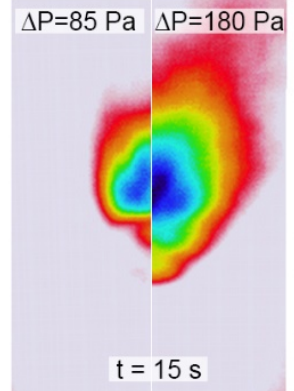

(b)

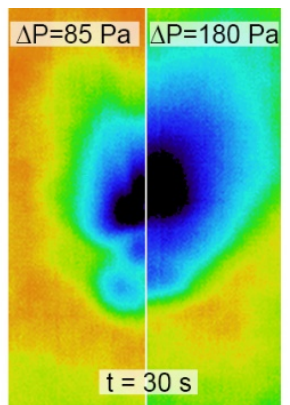

(c)

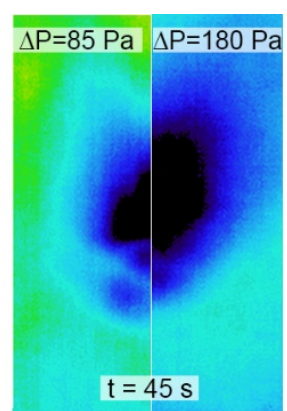

(d)

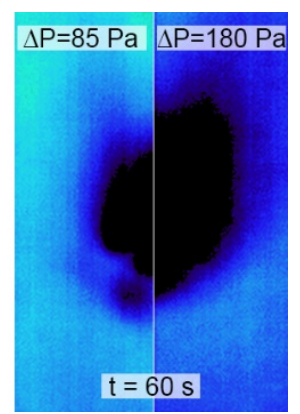

(e)

Figure 3. PP scenario (Day 4) with $\Delta \mathrm{P}=85 \mathrm{~Pa}$ (left) and $\Delta \mathrm{P}=180 \mathrm{~Pa}$ (right) for $t=0 \mathrm{~s}$ to $t=60 \mathrm{~s}$. 
The differences between active and passive IRT were evaluated in scenario PL. Figure 4 shows the thermal images of the PL scenario taken in Day 8, both with active and passive approaches. Similar results were obtained for the other days. A clear difference between the two procedures can be observed. Although possible to observe with passive IRT, active IRT highlights the phenomenon. In fact, with the active approach, air infiltration begins to be visible with a pressure difference of $25 \mathrm{~Pa}$, while with the passive one requires a higher pressure difference. In addition to this effect, the larger area of influence of the phenomenon is also exposed by active IRT. This is related with the increase of temperature differences between the exterior air and the surface of the cardboard sheet when the active approach is used. This is particularly interesting in moderate climates, with no heating habits, where a temperature difference between outdoor and indoor environments of at least $10{ }^{\circ} \mathrm{C}$, as recommended by the standards [2-4,58], is hardly achieved.

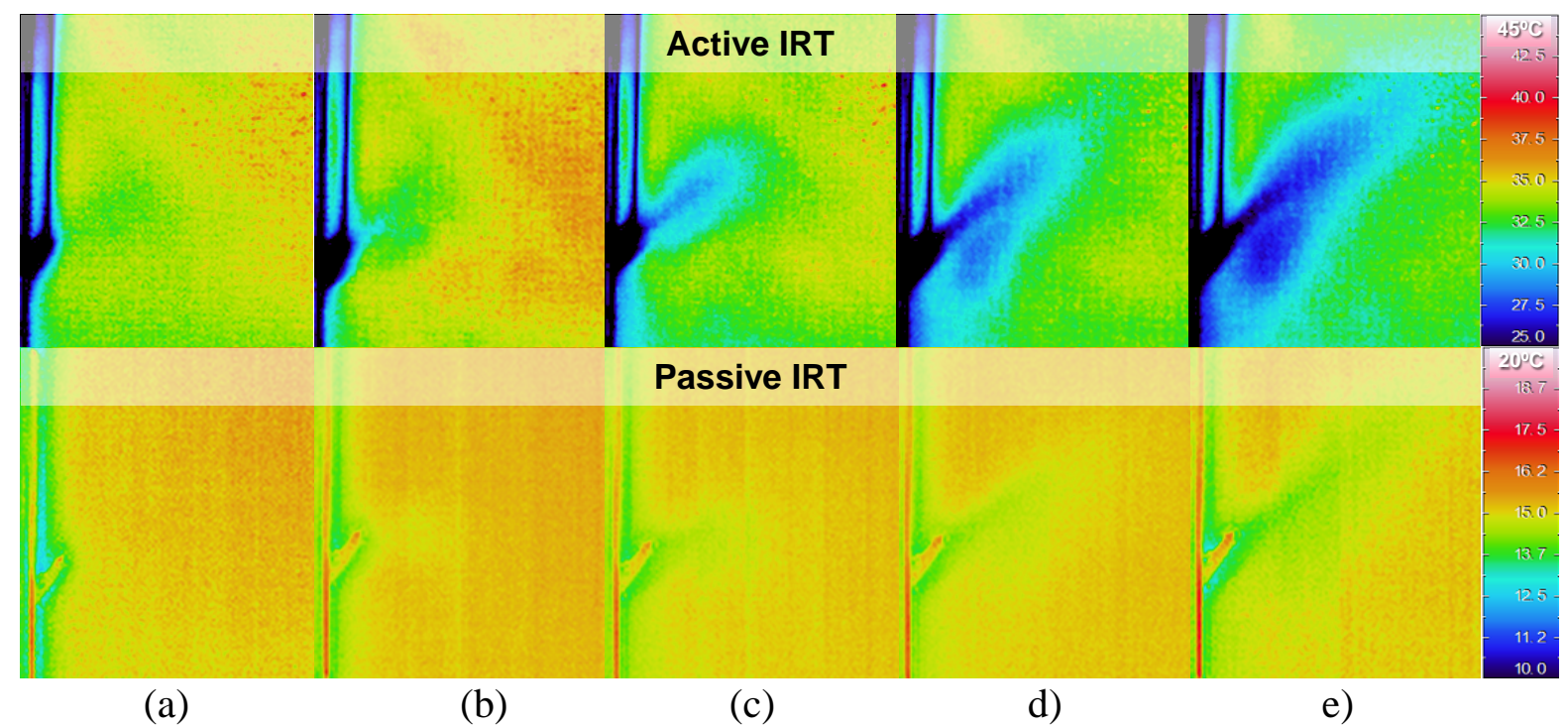

Figure 4: PL scenario (Day (d) $\Delta \mathrm{P}=175 \mathrm{~Pa}$; (e) $\Delta \mathrm{P}=225 \mathrm{~Pa}$.

\section{QUANTITATIVE ANALYSIS}

\subsection{Initial remarks}

The active thermography methodology used in this study is based on heating a cardboard sheet, through an artificial heat source, and register its temperature evolution. The qualitative analysis showed that the temperature distribution among the cardboard sheet is not homogeneous and thus the quantitative analysis was assessed to highlight this phenomenon. To that end, several different numerical approaches were tested, first for the PP scenario and afterwards for the PL one. Both scenarios should be understood as complementary, since they reflect the same phenomenon from different points of view, the perpendicular and lateral one.

In the PP scenario several numerical methods were used and compared, namely: average temperature of four concentric boxes; histograms of the thermal images; box plot representation of the superficial temperature; temperature profiles; histogram of the temperature differences; and thermograms subtraction. The layout of scenario PL does not allow testing as many methods, nevertheless it was compared the average temperature of three boxes and the percent temperature difference between the two extreme boxes. 


\subsection{Scenario $P P$}

In the first approach tested for the PP scenario, four concentric boxes (A, B, C and D) have been established and the corresponding average temperatures were calculated for $\triangle P=$ $85 \mathrm{~Pa}$ and $\Delta \mathrm{P}=180 \mathrm{~Pa}$ and for each time-step. The results are shown in Figure 5.

The box $\mathrm{D}$ is located in the central part of the thermogram, in front of the air infiltration. At $t=15 \mathrm{~s}$, this box has the largest temperature difference (considering $\Delta P=85 \mathrm{~Pa}$ and $\Delta P=$ $180 \mathrm{~Pa}$ ), around $5{ }^{\circ} \mathrm{C}$, which represents a decrease of $20 \%$ approximately. The lower temperature occurs for the higher pressure difference. Although similar results can be found in boxes $\mathrm{A}, \mathrm{B}$ and $\mathrm{C}$, these differences are less pronounced.

After $t=30 \mathrm{~s}$ the temperature drop is less marked, both for $\Delta P=85 \mathrm{~Pa}$ and $\Delta P=180 \mathrm{~Pa}$, corresponding to a stabilization of the temperature. These results point that the first 30 seconds of the experiment are critical.

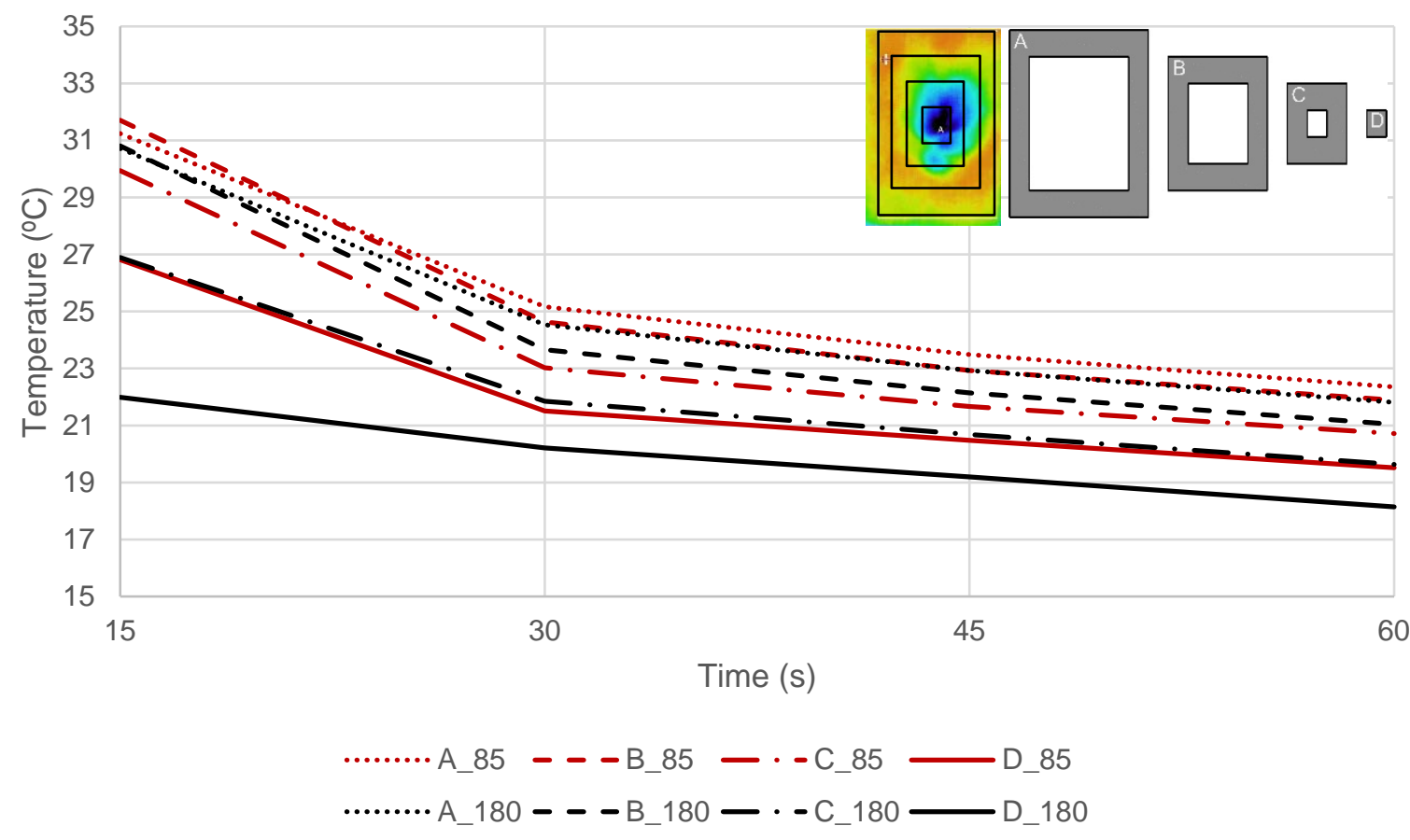

Figure 5. Average temperatures of thermograms in PP scenario (Day 4) with $\Delta P=85 \mathrm{~Pa}$ and $\Delta \mathrm{P}=180 \mathrm{~Pa}$ at instants $t=15, t=30, t=45$ and $t=60 \mathrm{~s}$.

Another possibility for the quantitative analysis of IRT is making use of histograms. The histogram of a thermogram represents the percent number of pixels at a certain temperature. A comparison between the histograms (Day 4) is shown in Figure 6, where the thick points represent the weighted average. For each pressure difference, it can be observed that the temperature drops with time as the curves are shifted to the left on the abscissa axis (temperature, ${ }^{\circ} \mathrm{C}$ ). Unlike Figure 5, in Figure 6 it is easily seen how the number of pixels for each temperature move to the left on the $\mathrm{X}$ axis and concentrated (towards a lower temperature). For the $\Delta P=180 \mathrm{~Pa}$ scenario, a greater decrease in temperature can be identified. The difference between the weighted average temperatures considering $\triangle P=180$ $\mathrm{Pa}$ and $\Delta \mathrm{P}=85 \mathrm{~Pa}$ is around $1^{\circ} \mathrm{C}$ for $t=30,45$ and $60 \mathrm{~s}$ and slightly less for $t=15 \mathrm{~s}$. Figure 6 also shows a reduction of the temperature range throughout the experiment $\left([20,27]^{\circ} \mathrm{C}\right.$ for $t=$ $30 \mathrm{~s},[20,25]^{\circ} \mathrm{C}$ for $t=45 \mathrm{~s}$ and $[20,24]{ }^{\circ} \mathrm{C}$ for $t=30 \mathrm{~s}$, when $\left.\Delta P=85 \mathrm{~Pa}\right)$, which confirms the increased uniformity of the superficial temperature due to cooling. 


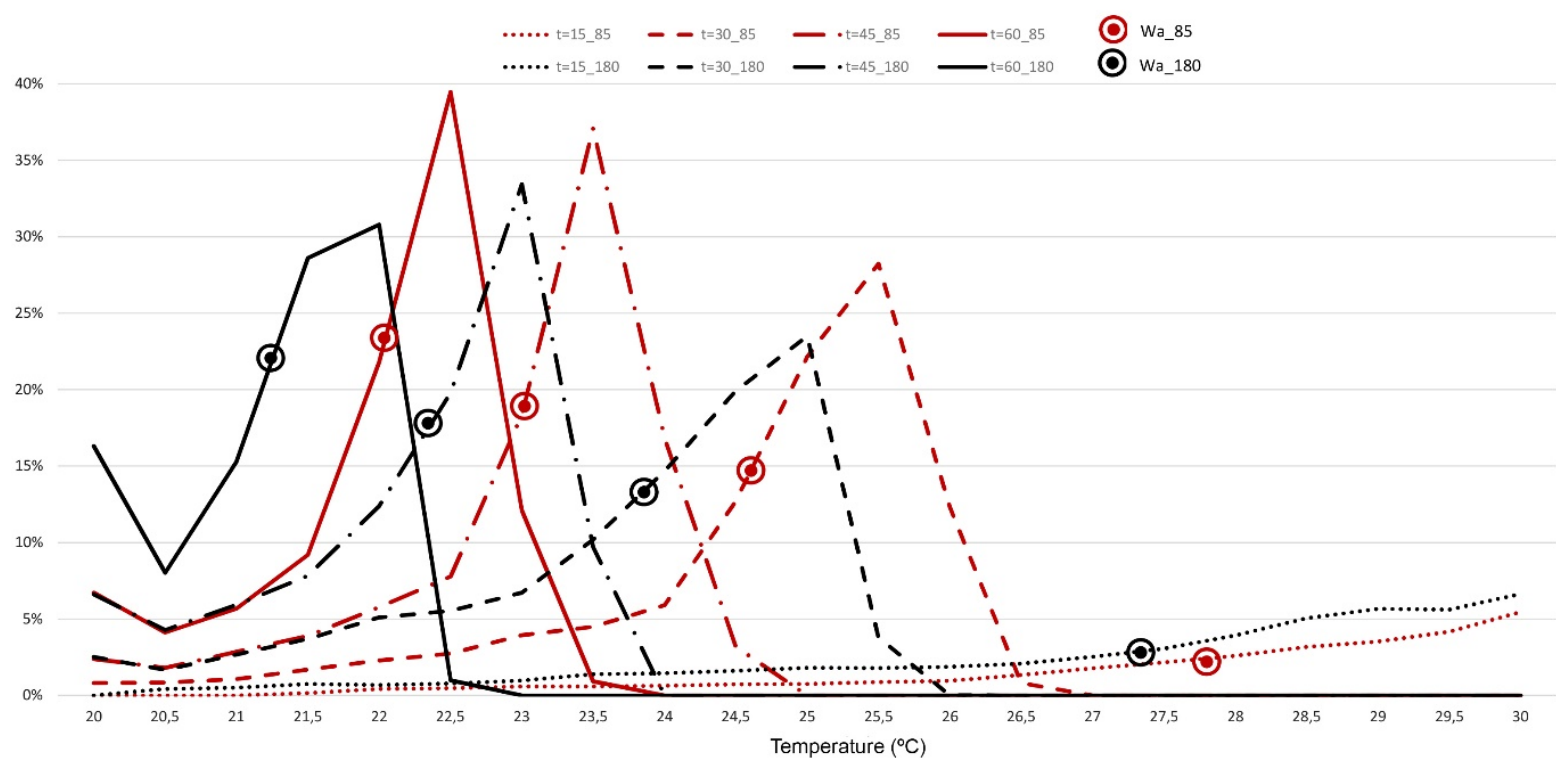

Figure 6. Histogram of thermograms in PP scenario (Day 4) with $\Delta P=85 \mathrm{~Pa}$ and $\Delta P=180$ Pa at instants $t=15, t=30, t=45$ and $t=60 \mathrm{~s}$. The thick points show the weighted average (Wa).

A different possibility is making use of the box plot representation of the superficial temperature. Figure 7a shows the box plots from $t=0$ to $t=60 \mathrm{~s}$. At the initial instant, the temperatures are extremely high due to the use of the heat source and can bias the interpretation. Thus, Figure 7b shows only the box plots from $t=15$ to $t=60 \mathrm{~s}$ and differences among them can now be observed in detail.

Besides the cooling effect throughout the experiment, in this representation, the wider spread of the superficial temperature found in the first instants can also be identified, especially for $t=15 \mathrm{~s}$. The results show that the median (Q2) is always lower when $\Delta P=180$ Pa. The largest difference between medians occurs for $t=15 \mathrm{~s}$ and corresponds to about $5 \%$. The same conclusion would be drawn if the other statistical indicators (quartiles) were used.

The distribution of temperatures recorded in each pixel of the thermogram is a continuous function, not discrete. Figure 7, with the box plots, allows identifying relevant statistical values such as the median, first and third quartiles, as well as discarding insignificant values. All this always with the aim of highlighting in an analytical way the complex physical phenomenon.
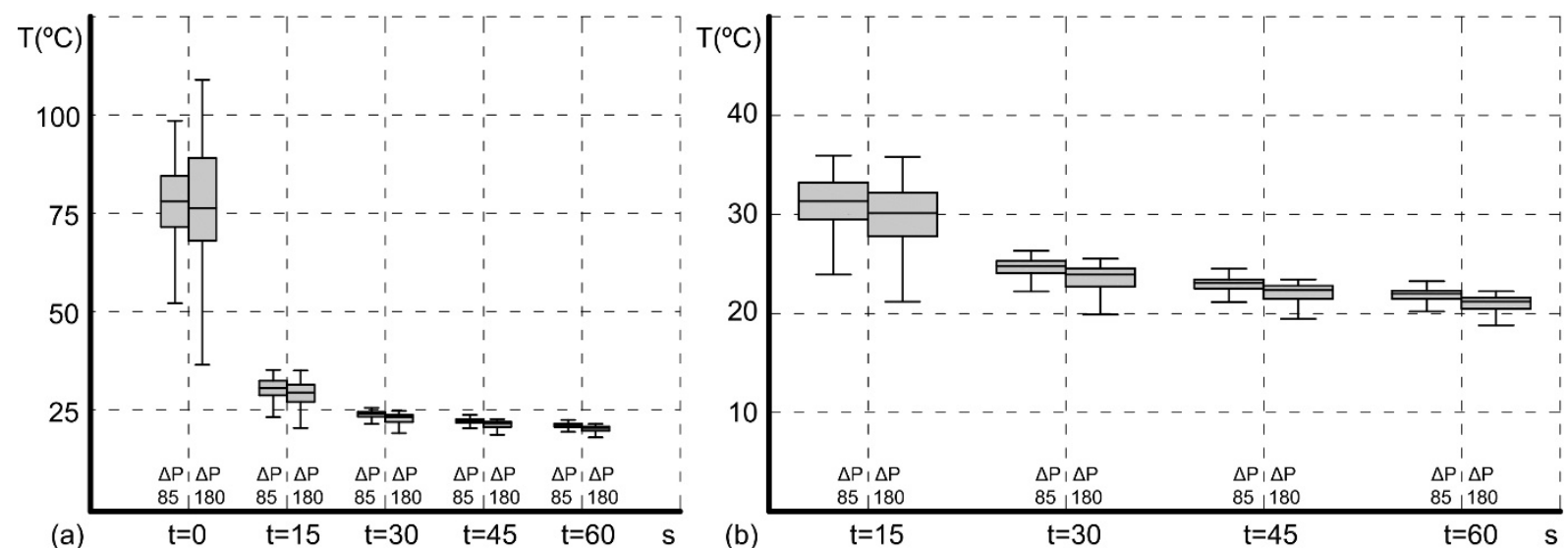
Figure 7. Box plots of the thermograms in $\mathrm{PP}$ scenario (Day 4) with $\Delta P=85 \mathrm{~Pa}$ and $\Delta P=$ $180 \mathrm{~Pa}$ (a) General view (from $t=0$ to $t=60 \mathrm{~s}$ ) and (b) detail of $t=15$ to $t=60 \mathrm{~s}$.

Temperature profiles can also be used to numerically analyse the thermograms. Figure 8 shows the temperature plot of a vertical and a horizontal profile and, once again, it is evident how the decrease of the temperature is more remarkable in the first instants and stabilizes for steps greater than $t=30 \mathrm{~s}\left(10{ }^{\circ} \mathrm{C}\right.$ for $t=15 \mathrm{~s}$ and $5{ }^{\circ} \mathrm{C}$ for $t=60 \mathrm{~s}$, approximately, for both pressure differences). The effect of the higher pressure can also be identified through the more pronounced temperature drop ( $\mathrm{V}$-shape). However, the phenomenon is not as evident as in the previous methods. On the other hand, unlike the previous ones, this method allows detecting the exact position of the air infiltration in the cardboard sheet. Throughout the experiment, as the temperature in the cardboard sheet becomes more homogeneous, the less pronounced $\mathrm{V}$ shape of the temperature curves observed for the $\Delta P=180 \mathrm{~Pa}$ is less evident because the thermal equilibrium is being reached.

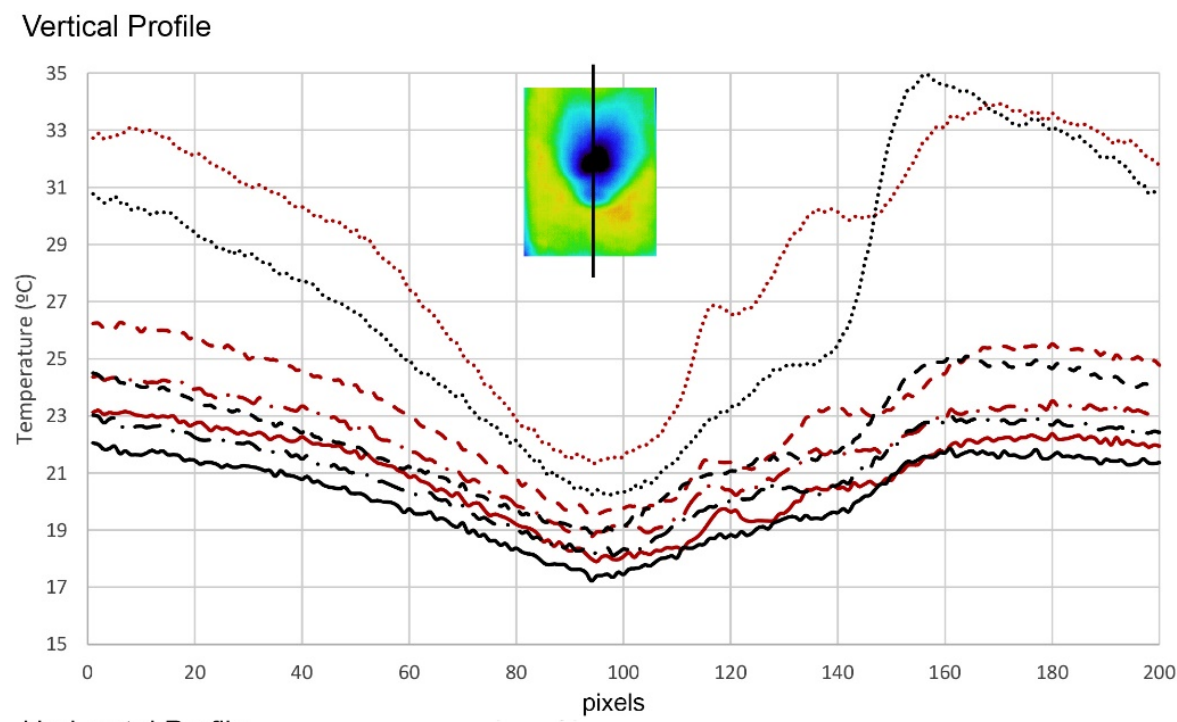

Horizontal Profile
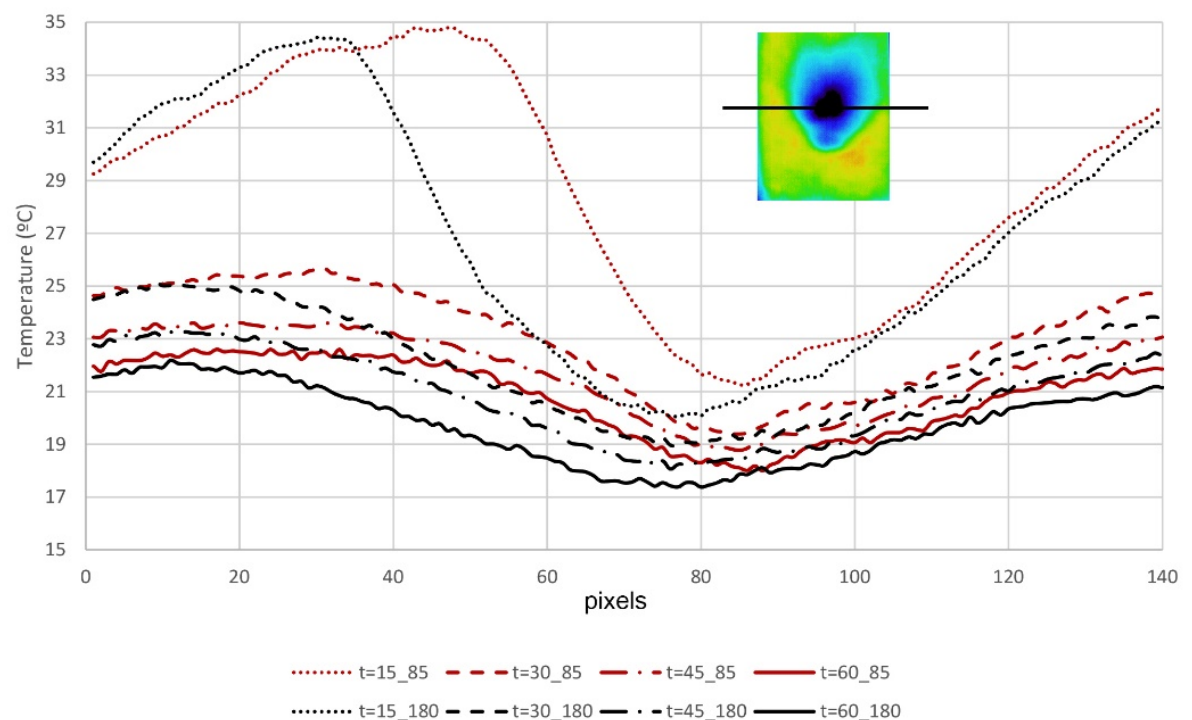

Figure 8. Vertical and horizontal profiles, $\mathrm{PP}$ scenario (Day 4) with $\Delta P=85 \mathrm{~Pa}$ and $\Delta P=180$ Pa at instants $t=15, t=30, t=45$ and $t=60 \mathrm{~s}$. 
The temperature differences between $\Delta P=180 \mathrm{~Pa}$ and $\Delta P=85 \mathrm{~Pa}$ were calculated on a pixel basis and the corresponding histogram was plotted (Figure 9). Two thermograms are required for each time step (one for $\Delta \mathrm{P}=180 \mathrm{~Pa}$ and another for $\Delta \mathrm{P}=85 \mathrm{~Pa}$ ). First of all, the pixel to pixel temperature variation is obtained. Then, Figure 9 groups the number of pixels with a certain temperature difference. If we keep constant other parameters, and modify the pressure difference, i.e., the $22 \%$ of the pixels for $\mathrm{t}=30$ s have had a temperature variation between -1.5 and $-2.0^{\circ} \mathrm{C}$. This procedure was performed for the entire area of the cardboard sheet. The main goal was to highlight the effect of using different pressure differences. The results show that the superficial temperature is lower for $\Delta \mathrm{P}=180 \mathrm{~Pa}$ as the majority of the temperature differences are negative, confirming that this is an efficient method of highlighting the phenomenon. Furthermore, the procedure also allows assessing the cooling phenomenon. In fact, for $t=15 \mathrm{~s}$ the temperature differences are equal or lower than $-1.5{ }^{\circ} \mathrm{C}$ in more than $50 \%$ of the image, while this percentage decreases to around $30 \%$ when $t=30 \mathrm{~s}$. As time passes, the differences between the temperatures for the two pressures are attenuated, ranging between -0.5 and $0{ }^{\circ} \mathrm{C}$ in more than $50 \%$ of the image, indirectly pointing to an equilibrium with the ambient temperature.

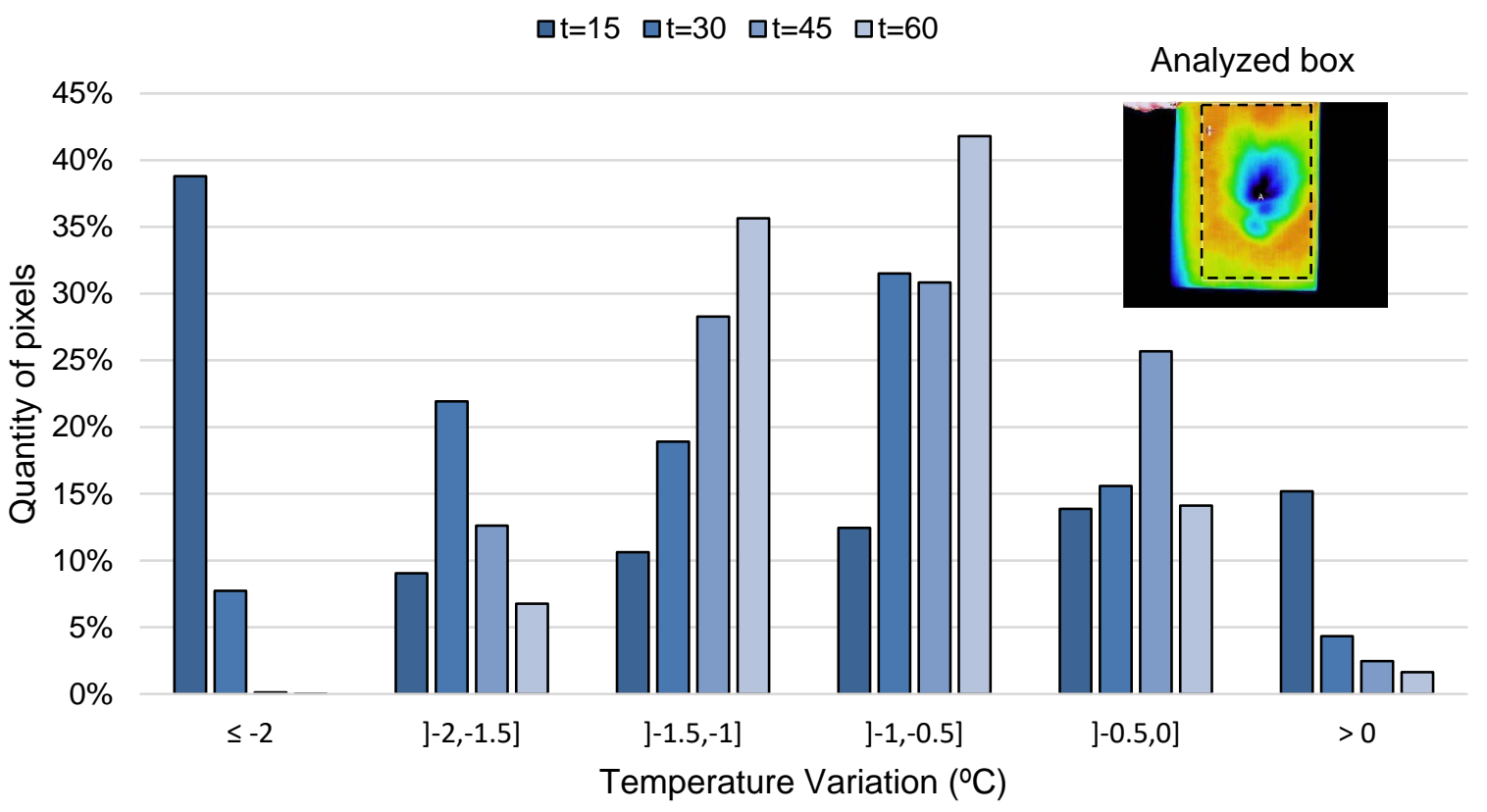

Figure 9. Number of pixels according to temperature variation in PP scenario with $\Delta \mathrm{P}=180 \mathrm{~Pa}$ and $\Delta \mathrm{P}=85 \mathrm{~Pa}$.

The last method tested in this scenario was the thermograms subtraction. Two possibilities were tried: (a) subtraction between each thermogram and the one at $\mathrm{t}=15 \mathrm{~s}$ (Figure 10a); and (b) subtraction between each thermogram and its previous (Figure 10b). The thermograms taken at $t=0 \mathrm{~s}$ were not used in this analysis because their significantly higher temperature would bias the conclusions. The evolution of temperature contrasts and the cooling caused by the exterior air can also be assessed through this technique.

The results of procedure (a) show that, throughout the experiment, the temperature in the central region of the cardboard sheet is approximately constant, confirming that the initial 15 $\mathrm{s}$ are crucial for the cooling of this area. On the other hand, the superficial temperature in the outer area is decreasing as the darker region of the thermogram is increasing. The effect of applying different pressure differences is not as clear as in the previous methods, since there 
are no relevant differences between the two images. The rapid decrease of the cooling rate is obvious in procedure (b) as the thermal images are more homogeneous after $t=30 \mathrm{~s}$.

(a)
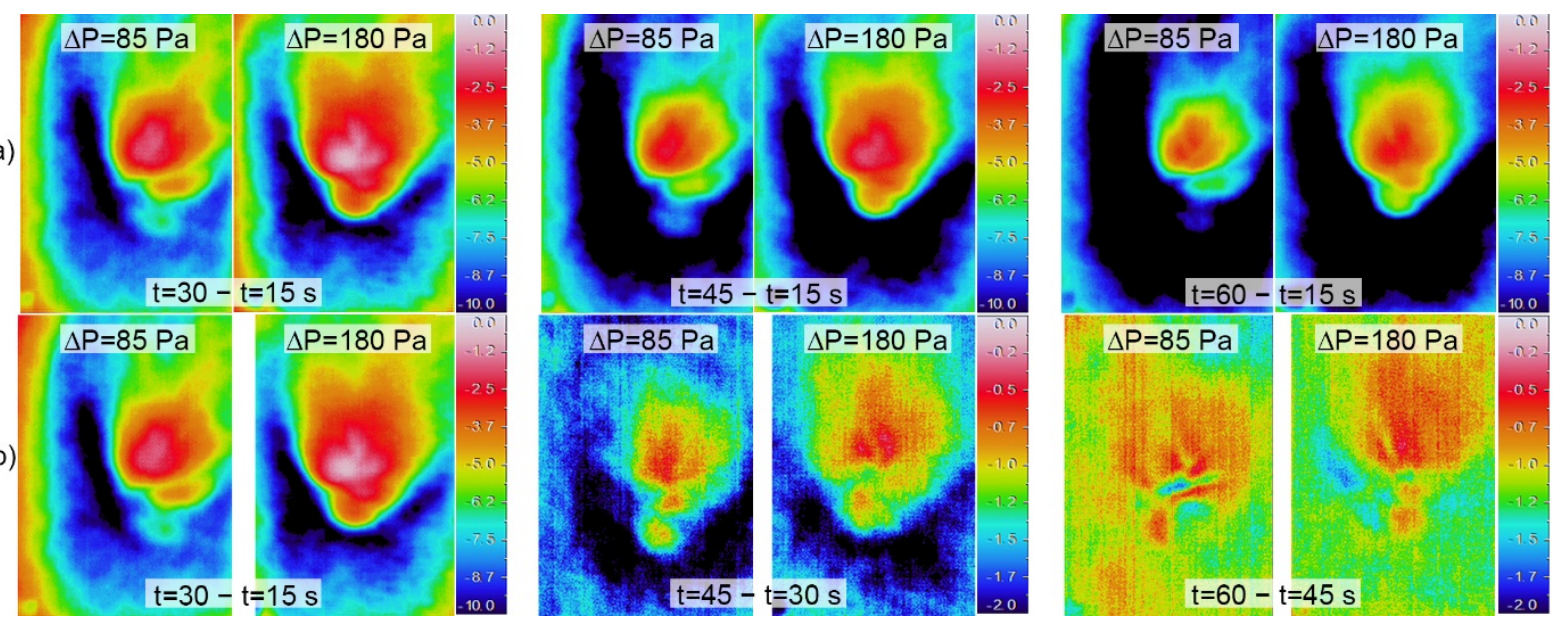

Figure 10. Thermograms subtraction in PP scenario (Day 4) for $\Delta P=85 \mathrm{~Pa}$ (left) and $\Delta P=180 \mathrm{~Pa}$ (right): (a) subtraction between each thermogram and the one at $t=15 \mathrm{~s}$; (b) subtraction between each thermogram and its previous.

\subsection{Scenario $P L$}

In this scenario, the first quantitative method includes the definition of three areas in the thermogram (boxes A, B and C, with box A being the one located closer to the air inlet). The analysis of the thermograms for days 5 to 8 are shown in Figure 11. Days 1 to 4 were not included in the analysis, as they do not provide further information.

As expected, the average temperature in box $\mathrm{A}$ is always lower, followed by box $\mathrm{B}$ and finally box $\mathrm{C}$, in line with their distance to the air inlet. In fact, the results of day 8 show that throughout the experiment the average temperature of Box $C$ decreased $4 \%$, while in boxes $B$ and $\mathrm{A}$ this value was $6 \%$ and $9 \%$, respectively. Moreover, this method shows that the temperature gradient is enhanced by an increased pressure difference. For instance, the results of day 8 show that the average temperature of box $A$ is $5 \%$ lower than the one of box $C$ when $\Delta P=25 \mathrm{~Pa}$. This percentage increases up to $9 \%$ when the pressure difference increases to $\Delta P$ $=225 \mathrm{~Pa}$.

Overall, two sub-sets can be identified in the sample: days 6 and 7, with an approximately constant performance, and days 5 and 8, where the temperature drop is much more visible. This difference occurs due to exterior temperature, which is significantly lower in days 5 and 8 (Table 3). If one compares the results between days 5 and 8, a higher initial temperature can be identified in day 8 , leading to a more pronounced reduction of the superficial temperature. This is particularly noticeable in boxes $\mathrm{B}$ and $\mathrm{C}$ while, in box $\mathrm{A}$, the difference is less marked, confirming the fast cooling phenomenon that occurs near the inlet device. Regarding days 6 and 7, boxes $B$ and $C$ exhibit an almost constant temperature and, therefore, the cooling effect is only visible in box A, particularly for higher pressure differences. These results, not only confirm the importance of guaranteeing an adequate temperature gradient between indoor and outdoor, but also point out that when this gradient is not sufficient it can be offset by an increased pressure difference. 


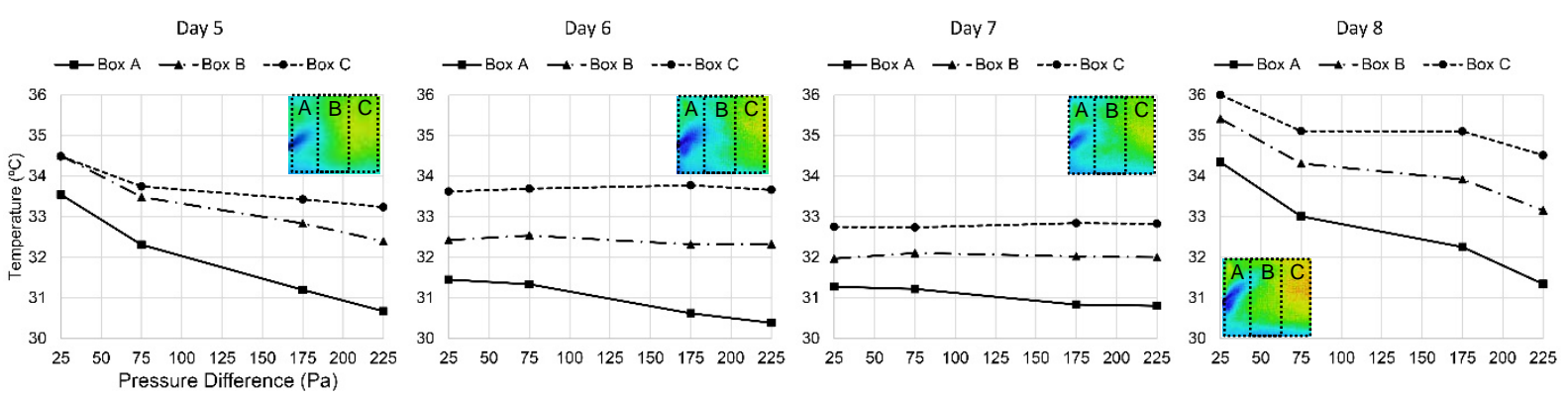

Figure 11. Average temperature of thermograms in PL scenario (Days 5, 6, 7 and 8) with $\Delta \mathrm{P}=25 \mathrm{~Pa}$ to $\Delta \mathrm{P}=225 \mathrm{~Pa}$, for boxes $\mathrm{A}, \mathrm{B}$ and $\mathrm{C}$.

The same boxes were used to test another method. In this case, the percent temperature difference between boxes $A$ and $C$ was calculated (Figure 12). Once again, only Days 5, 6, 7 and 8 were used. When compared to the previous method, the same conclusions can be drawn from this graph. However, its interpretation is not as straightforward. The main advantage of this representation is quantifying the cooling effect near the inlet when compared to the outer region of the cardboard sheet. For the lower pressure difference $(\triangle P=25 \mathrm{~Pa})$, the temperature gradient ranges between $-2.7 \%$ and $-6.5 \%$, increasing up to $-6.2 \%$ and $-9.7 \%$, when $\Delta P=225$ Pa.

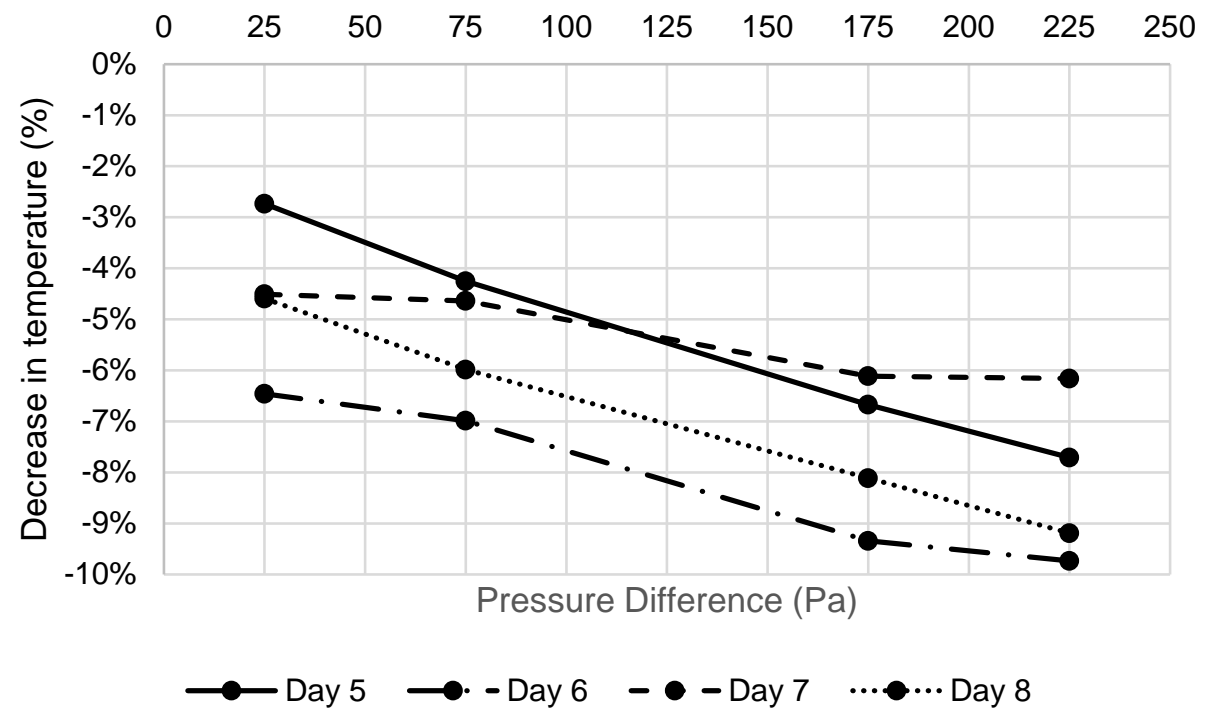

Figure 12. Percent temperature difference between boxes A and C in PL scenario (Days 5, 6, 7 and 8) with $\Delta \mathrm{P}=25 \mathrm{~Pa}$ to $\Delta \mathrm{P}=225 \mathrm{~Pa}$.

\subsection{Scenario $P L$}

In this scenario, the first quantitative method includes the definition of three areas in the thermogram

\section{CONCLUSIONS}

The results of this work allow a step forward in the knowledge of applying IRT to assess leakage points in the buildings envelope. In fact, through two different scenarios (PP and PL) 
selected in a real case study, measurements were performed using both active and passive IRT. The results were evaluated both in a qualitative approach, by comparing active and passive IRT, and in a quantitative one, by testing different numerical methods. These enable a detailed discussion concerning the opportunities and constraints of using IRT to study the airtightness phenomenon.

Qualitatively, it was possible to evaluate the cooling effect of time and increased pressure difference. Through scenario PP, for both pressure differences, the air leakage was detected by a more pronounced decrease of the cardboard sheet surface temperature in the area aligned with the airflow. When the pressure difference increases throughout the experiment, the temperature decreases faster as the colder area in the thermograms increases. Furthermore, a significant temperature drop is already observed in the initial instants $(\mathrm{t}=15 \mathrm{~s})$. It was also possible to highlight the differences between active and passive IRT using scenario PL. Similar results were obtained in the two approaches, however, active IRT allows for clearer results, not only in terms of thermal contrast but also in terms of affected area. This is particularly interesting in climates with no heating habits, where only small temperature difference between outdoor and indoor are achieved.

Different numerical methods were used and compared for the quantitative analyses. PP scenario enabled a more detailed discussion as six methods were test. The layout of scenario PL only allowed testing two different methods.

The first approach tested for the PP scenario was analysing the average temperatures of four concentric boxes for the two pressures under study and for each time-step. The box located in the central part of the thermogram and aligned with the air infiltration always presented lower temperatures. The temperature drop was sharper in the first seconds, as after $t$ $=30 \mathrm{~s}$ its stabilization can be seen. This indicates that the first seconds of the experiment are critical. On the other hand, as expected, the lower temperatures always occur for the higher pressure difference.

The use of histograms highlighted that the temperature drops with time as the curves are shifted to the left on the temperature axis. For higher pressure differences, the decrease in temperature is higher. One the other hand, histograms also allow observing a decrease of the temperature range throughout the experiment, which is related with cooling effect that increases the uniformity of the superficial temperature. As in the previous method, also the use of box plot representation enables to detect the cooling effect, the larger variability of the superficial temperature in the first instants and the impact of the pressure difference. However, the best method to highlight the effect of using different pressure differences was plotting a histogram of the temperature differences between $\Delta \mathrm{P}=180 \mathrm{~Pa}$ and $\Delta \mathrm{P}=85 \mathrm{~Pa}$ on a pixel basis.

The main advantage of temperature profiles is allowing detecting the position of the air infiltration in the cardboard sheet, which was not possible in the previous ones. However, the effect of the pressure difference is more difficult to be detected. The evolution in time of surface temperature on the cardboard sheet can also be assessed, as the slope of the profile decreases throughout the experiment.

Also, the thermograms subtraction allows detecting the position of the air infiltration. The main advantages of this method is to display as a thermal image the evolution of temperature contrasts and the cooling caused by the exterior air. However, and just like the profiles, it is not as efficient to highlight the effect of applying different pressure differences.

The quantitative analysis of scenario PL using three boxes that divide the thermograms into three sections enable to detect a colder area near the air leakage point and higher temperatures on the furthest area. Moreover, the temperature gradient was always higher when the pressure difference increased. The method also allowed confirming the importance the temperature gradient between indoor and outdoor to obtain clearer results. However, it 
also point out that when this gradient is not sufficient it can be offset by an increased pressure difference. The percent temperature difference between the area near the inlet and the furthest one allowed quantifying the cooling effect of the air infiltration.

In conclusion, active IRT, when combined with pressure differences, has demonstrated to be an effective methodology for detecting air infiltrations. In the quantitative approach, different numerical methods can be used. Their selection depends on the aims of the study, as they can highlight different perspectives of the phenomenon. In this research, i.e., the average temperature of the thermograms has been calculated based on time in order to quantify the temperature variation.

\section{ACKNOWLEDGEMENTS}

This work was financially supported by: Project POCI-01-0145-FEDER-007457 CONSTRUCT - Institute of R\&D In Structures and Construction funded by FEDER funds through COMPETE2020 - Programa Operacional Competitividade e Internacionalização (POCI) - and by national funds through FCT - Fundação para a Ciência e a Tecnologia.

\section{REFERENCES}

[1] Spanish Standard CTE-HE Documento Básico Ahorro de Energía. Ministerio de Fomento (2017). https://www.codigotecnico.org/images/stories/pdf/ahorroEnergia/DccHE.pdf

[2] Residential Energy Services Network RESNET Interim Guidelines for Thermographic Inspections of Buildings, April 4, 2012 Residential Energy Services Network, Oceanside CA, US (2012).

[3] ISO 6781, Thermal Insulation - Qualitative detection of thermal irregularities in building envelopes - Infrared method, International Organization for Standardization, 1983.

[4] CEN-EN 13187, Thermal performance of buildings - Qualitative detection of thermal irregularities in building envelops - Infrared method, European Committee for Standardization, 1998.

[5] M. Pinto, J. Viegas, V.P. de Freitas, Air permeability measurements of dwelling sand building components in Portugal, Build. Environ. 46 (2011) 2480-2489.

https://doi.org/10.1016/j.buildenv.2011.06.009.

[6] Fernández-Agüera, Jesica; Sendra, Juan José; Domínguez, Samuel. Protocols for measuring the airtightness of multi-dwelling units in Southern Europe. Procedia Engineering. Vol. 21. pp. 98-105, 2011. http://dx.doi.org/10.1016/j.proeng.2011.11.1992.

[7] E. Barreira, R.M.S.F. Almeida, M. Moreira. An infrared thermography passive approach to assess the effect of leakage points in building, Energy and Buildings 140 (2017) 224-235. https://doi.org/10.1016/j.enbuild.2017.02.009.

[8] C.E.N. EN 13829, Thermal Performance of Buildings - Determination of Air Permeability of Buildings - Fan Pressurization Method, CEN - European Committee for Standardization, Brussels, 2001.

[9] J.M. Hart, A Practical Guide to Infra-Red Thermography for Building Surveys, Building Research Establishment, Watford, 1991. 
[10] C.A. Balaras, A.A. Argiriou, Infrared thermography for building diagnostics, Energy Build. 34 (2002) 171-183. https://doi.org/10.1016/S0378-7788(01)00105-0.

[11] F. Asdrubali, G. Baldinelli, F. Bianchi, A quantitative methodology to evaluate thermal bridges in buildings, Appl. Energy 97 (2012) 365-373.

https://doi.org/10.1016/j.apenergy.2011.12.054.

[12] D. Katunsky, A. Korjenic, J. Katunska, M. Lopusniak, S. Korjenic, S. Doroudiani, Analysis of thermal energy demand and saving in industrial buildings: a case study in Slovakia, Build. Environ. 67 (2013) 138-146. https://doi.org/10.1016/j.buildenv.2013.05.014.

[13] R.W.F. Cameron, J.E. Taylor, M.R. Emmett, What's 'cool' in the world of green façades: how plant choice influences the cooling properties of green walls, Build. Environ. 73 (2014) 198-207. https://doi.org/10.1016/j.buildenv.2013.12.005.

[14] P. De Berardinis, M. Rotilio, C. Marchionni, A. Friedman, Improving the energyefficiency of historic masonry buildings A case study: a minor centre in the Abruzzo region, Italy, Energy Build. 80 (2014) 415-423. https://doi.org/10.1016/j.enbuild.2014.05.047.

[15] B.Lehmanna, K.Ghazi Wakili, Th.Frank, B.Vera Collado, Ch.Tanner, Effects of individual climatic parameters on the infrared thermography of buildings, Applied Energy 110 (2013) 29-43. https://doi.org/10.1016/j.apenergy.2013.03.066

[16] D. González-Aguilera, S. Lagüela, P. Rodríguez-Gonzálvez, D. Hernández-López, Image-based thermographic modeling for assessing energy efficiency of buildings façades, Energy Build. 65 (2013) 29-36. https://doi.org/10.1016/j.enbuild.2013.05.040.

[17] C. Lerma, Á. Mas, E. Gil, J. Vercher, M.J. Peñalver. Pathology of building materials in historic buildings. Relationship between laboratory testing and infrared thermography. Materiales de Construcción 64 (313), 009 (2014). http://dx.doi.org/10.3989/mc.2013.06612.

[18] M.Y.L. Chew. Assessing building façades using infra-red thermography, Struct. Surv. 16 (1998) 81-86.

[19] E. Barreira, V.P. de Freitas, Evaluation of building materials using infrared thermography, Constr. Build. Mater. 21 (2007) 218-224.

https://doi.org/10.1016/j.conbuildmat.2005.06.049.

[20] F. Cerdeira, M.E. Vázquez, J. Collazo, E. Granada, Applicability of infrared thermography to the study of the behaviour of stone panels as building envelopes, Energy Build. 43 (2011) 1845-1851. https://doi.org/10.1016/j.enbuild.2011.03.029.

[21] S.S. de Freitas, V.P. de Freitas, E. Barreira, Detection of façade plaster detachments using infrared thermography - A nondestructive technique, Constr. Build. Mater. 70 (2014) 80-87. https://doi.org/10.1016/j.conbuildmat.2014.07.094.

[22] P. Theodorakeas, N.P. Avdelidis, E. Cheilakou, M. Koui, Quantitative analysis of plastered mosaics by means of active infrared thermography, Constr. Build.Mater. 73 (2014) 417-425. https://doi.org/10.1016/j.conbuildmat.2014.09.089.

[23] Y.H. Jo, C.H. Lee, Quantitative modeling and mapping of blistering zone of the Magoksa Temple stone pagoda (13th century, Republic of Korea) by graduated heating thermography, Infrared Phys. Technol. 65 (2014) 43-50. https://doi.org/10.1016/j.infrared.2014.02.011.

[24] A. Menezes, M. Glória Gomes, I. Flores-Colen, In-situ assessment of physical performance and degradation analysis of rendering walls, Constr. Build. Mater. 75 (2015) 283-292. https://doi.org/10.1016/j.conbuildmat.2014.11.039. 
[25] M. Fox, D. Coley, S. Goodhew, P. De Wilde, Time-lapse thermography for building defect detection, Energy Build. 92 (2015) 95-106.

https://doi.org/10.1016/j.enbuild.2015.01.021.

[26] E. Rosina, N. Ludwig, Optimal thermographic procedures for moisture analysis in building materials, Proceedings of society of photographic instrumentation engineers (SPIE) 3827 (1999) 22-33.

[27] A. Moropoulou, N.P. Avdelidis, G. Haralampopoulos, S. Anagnostopoulou, Detection of moisture in porous materials by infrared thermography, Proceedings of society of photographic instrumentation engineers (SPIE) 4710 (2002) 324-332.

[28] N.P. Avdelidis, A. Moropoulou, P. Theoulakis, Detection of water deposits andmovement in porous materials by infrared imaging, Infrared Phys. Technol. 44(2003) 183-190. https://doi.org/10.1016/S1350-4495(02)00212-8.

[29] E. Grinzato, G. Cadelano, P. Bison, Moisture map by IR thermography, J. Mod. Opt. 57 (2010) 1770-1778. http://dx.doi.org/10.1080/09500341003731597.

[30] E. Grinzato, N. Ludwig, G. Cadelano, M. Bertucci, M. Gargano, P. Bison, Infrared thermography for moisture detection: a laboratory study and in-situ test, Mater. Eval. (2011) 2011.

https://ndtlibrary.asnt.org/2011/InfraredThermographyforMoistureDetectionALaboratoryStud yandInsituTest.

[31] P. Bison, G. Cadelano, L. Capineri, D. Capitani, U. Casellato, P. Faroldi, et al.,Limits and advantages of different techniques for testing moisture content in masonry, Mater. Eval. (2011) 2011.

https://ndtlibrary.asnt.org/2011/LimitsandAdvantagesofDifferentTechniquesforTestingMoistu reContentinMasonry.

[32] E. Barreira, R.M.S.F. Almeida, J.M.P.Q. Delgado, Infrared thermography forassessing moisture related phenomena in building components, Constr. Build. Mater. 110 (2016) 251269. https://doi.org/10.1016/j.conbuildmat.2016.02.026.

[33] E. Edis, I. Flores-Colen, J. de Brito, Passive thermographic detection of moisture problems in façades with adhered ceramic cladding, Constr. Build. Mater. 51 (2014) 187-197. https://doi.org/10.1016/j.conbuildmat.2013.10.085.

[34] E. Gil, C. Lerma, J. Vercher, Á. Mas. Methodology for Thermal Behaviour Assessment of Homogeneous Façades in Heritage Buildings. Journal of Sensors, 2017.

https://doi.org/10.1155/2017/3280691.

[35] N.P. Avdelidis, A. Moropoulou, Applications of infrared thermography for theinvestigation of historic structures, J. Cult. Herit. 5 (2004) 119-127.

https://doi.org/10.1016/j.culher.2003.07.002.

[36] A. Tavukcuoglu, A. Duzgunes, S. Demirci, E.N. Caner-Saltık. The assessment of a roof drainage system for an historical building, Build. Environ. 42 (2007) 2699-2709.

https://doi.org/10.1016/j.buildenv.2006.07.012.

[37] D. Paoletti, D. Ambrosini, S. Sfarra, F. Bisegna, Preventive thermographic diagnosis of historical buildings for consolidation, J. Cult. Herit. 14 (2013) 116-121.

https://doi.org/10.1016/j.culher.2012.05.005. 
[38] F. Ascione, N. Bianco, R.F. De Masi, F. de Rossi, G.P. Vanoli, Energy retrofit of an educational building in the ancient center of Benevento: feasibility study of energy savings and respect of the historical value, Energy Build. 95 (2015)172-183.

https://doi.org/10.1016/j.enbuild.2014.10.072.

[39] ASTM, Standard Practice for Thermographic Inspection of Insulation Installations in Envelope Cavities of Frame Buildings. ASTM-C 1060-90, American Society for Testing and Materials, USA, 2003.

[40] A. Ghahramani, G. Castro, S.A. Karvigh, B. Becerik-Gerber, Towards unsupervised learning of thermal comfort using infrared thermography, Applied Energy 211 (2018) 41-49.

[41] T. Kalamees, Air tightness and air leakages of new lightweight single-family detached houses in Estonia, Build. Environ. 42 (2007) 2369-2377.

https://doi.org/10.1016/j.buildenv.2006.06.001.

[42] T. Taylor, J. Counsell, S. Gill, Energy efficiency is more than skin deep: improving construction quality control in new-build housing using thermography, Energy Build. 66 (2013) 222-231. https://doi.org/10.1016/j.enbuild.2013.07.051.

[43] D.J. Titman, Applications of thermography in non-destructive testing of structures, NDT \& E Int. 34 (2001) 149-154. https://doi.org/10.1016/S0963-8695(00)00039-6.

[44] S. Martín Ocaña, I. Cañas Guerrero, I. González Requena, Thermographic survey of two rural buildings in Spain, Energy Build. 36 (2004) 515-523.

https://doi.org/10.1016/j.enbuild.2003.12.012.

[45] P.S.M. Wahlgren, E. Sikander, Methods and Materials for an Airtight Building. Thermal Performance of the Exterior Envelopes of Whole Buildings XI International Conference. Florida, USA (2010).

[46] ISO, Thermal Insulation-Qualitative Detection of Thermal Irregularities in Building Envelopes-Infrared Method. ISO 6781, International Organization for Standardization, Geneva, Switzerland, 1983.

[47] CEN, Thermal Performance of Buildings -Qualitative Detection of Thermal Irregularities in Building Envelops - Infrared Method. EN 13187, CEN -European Committee for Standardization, Brussels, 1998.

[48] ISO, Thermal performance of buildings-Determination of air permeability of buildings-Fan pressurization method. ISO 9972, International Organization for Standardization, Geneva, Switzerland, 2015.

[49] F. López, V. P. Nicolau, C. Ibarra-Castanedo, X. Maldague. Thermal e numerical model and computational simulation of pulsed thermography inspection of carbon fiber-reinforced composites. International Journal of Thermal Sciences 86 (2014) 325e340. http://dx.doi.org/10.1016/j.ijthermalsci.2014.07.015.

[50] C.A. Alvarez-Restrepo, H.D. Benitez-Restrepo, L.E. Tobón. Characterization of defects of pulsed thermography inspections by orthogonal polynomial decomposition. NDT and E International 91 (2017) 9-21. http://dx.doi.org/10.1016/j.ndteint.2017.05.003.

[51] R. Olmi, G. Inglese. A Procedure for Detecting Hidden Surface Defects in a Thin Plate by Means of Active Thermography. Journal of Nondestructive Evaluation. Sep 2017. http://dx.doi.org/10.1007/s10921-017-0440-6. 
[52] Q.H. Tran, D. Han, C. Kang, A. Haldar, J. Huh. Effects of Ambient Temperature and Relative Humidity on Subsurface Defect Detection in Concrete Structures by Active Thermal Imaging. Journal of Sensors (2017). http://dx.doi.org/10.3390/s17081718.

[53] B. Oswald-Tranta. Comparative study of thermal contrast and contrast in thermal signal derivatives in pulse thermography. NDT and E International 91 (2017) 36-46. http://dx.doi.org/10.1016/j.ndteint.2017.06.005.

[54] A. Thiam, J.C. Kneip, E. Cicala, Y. Caulier, J.M. Jouvard, S. Mattei. Modelling and optimization of open crack detection by flying spot thermography. NDT\&E International 89 (2017) 67-73. http://dx.doi.org/10.1016/j.ndteint.2017.03.010.

[55] R. Olmi, G. Inglese. Measurement of the external parameters in quantitative active thermography. Meas. Sci. Technol. 28 (2017). https://doi.org/10.1088/1361-6501/aa7ce1.

[56] C. Serra, A. Tadeu, N. Simoes. Boundary element method simulation of 3D heat diffusion in defective layered media for IRT building applications. Engineering Analysis with Boundary Elements, 2017. http://dx.doi.org/10.1016/j.enganabound.2017.05.005.

[57] A.P. Chrysafi, N. Athanasopoulos, N.J. Siakavellas. Damage detection on composite materials with active thermography and digital image processing. International Journal of Thermal Sciences 116 (2017) 242-253. http://dx.doi.org/10.1016/j.ijthermalsci.2017.02.017.

[58] ASTM-C 1060-90, Standard practice for thermographic inspection of insulation installations in envelope cavities of frame buildings, ASTM International, 2003. 